\title{
Occupational Risk Exposures and Adverse Health Findings Among Farmers in Southern Philippines
}

\author{
Jinky Leilanie Lu, $\mathrm{MOH}, \mathrm{PhD}^{1}$ and Emma K. Salas, $\mathrm{PhD}^{2}$ \\ ${ }^{1}$ National Institutes of Health, University of the Philippines Manila \\ ${ }^{2}$ Department of Agriculture, University of Southern Mindanao, Kabakan, North Cotabato
}

\begin{abstract}
Introduction. Pesticides are widely used in the agricultural sector to increase production by cutting costs and improving product quality. However, these chemicals come with serious health effects when individuals are exposed to large quantities at once or low amounts over time.
\end{abstract}

Objective. This study aimed to identify the health symptoms and physical assessment findings affecting farmers from their repeated occupational exposure to pesticides in a rural region in the Philippines.

Methods. This research study used a cross-sectional design, and samples were drawn based on a multistage sampling of 387 agricultural workers. The target site was in the southern Philippines, and the sample was selected randomly from the identified municipalities. Survey questionnaires were given to the respondents, and a physical assessment was made by medical doctors and trained registered nurses. The data were encoded using SPSS ${ }^{\mathrm{TM}}$ 13.0. The statistics used were both descriptive and inferential.

Results. The farmers used pesticides in their farms with an average of 2.3 days per week (SD: 2.13 ). The mean total spraying time was 3.07 hours (SD: \pm 14.76 ) per day. The average amount of pesticide used in an application was 1.33 L per application (SD: \pm 6.53 ). Sixty-three percent (63\%) had spills while spraying, and $47 \%$ reported having spilled pesticides while mixing. Farmers were assessed and found to have experienced symptoms and exhibited physical assessment findings surrounding the following body systems: general, EENT, neurologic, gastrointestinal, respiratory, cardiovascular, and integumentary systems. Abnormalities in laboratory parameters were also observed among the respondents. The mini-mental state examination was done to test if the respondents showed signs of cognitive impairment. The results showed that most respondents (93.95\%) had normal cognitive function, while $6.05 \%$ of respondents had some level of cognitive impairment. Associations were also tested using Phi Coefficient, and certain pesticide exposure variables were associated with farmers' physical findings and symptoms experienced by farmers.

Conclusion. This study translates pesticide's health impact by identifying the common symptoms experienced by farmers and concerning physical assessment findings. The study found that farmers suffered from various symptoms concerning the general health, eye, ears, nose, and throat region, neurological system, gastrointestinal system, respiratory system, cardiovascular system, and the integumentary system. In addition, the laboratory parameters of the participants also exhibited abnormalities indicative of exposure and possible adverse effects from pesticides.

Key Words: farmers, agricultural workers, occupational health and safety, pesticides

\section{INTRODUCTION}

Corresponding author: Jinky Leilanie Lu, MOH, PhD National Institutes of Health University of the Philippines Manila

623 Pedro Gil Street, Ermita, Manila 1000, Philippines Email: jinky_lu@yahoo.com
Pesticides are widely used in the agricultural sector to increase production by cutting costs and improving product quality. However, these chemicals come with serious health effects when an individual is exposed to large quantities at once or low amounts over time. ${ }^{1}$ In addition to this, safe pesticide handling is not strictly enforced, especially in 
developing countries. Developed countries have stricter regulations by banning dangerous pesticide products. However, these prohibited chemicals may still be sold in developing ones, increasing the health risk attached to the handling of pesticides within these countries. Moreover, these farmers often do not comply with the safe dosages and mixing proportions of the pesticides used. ${ }^{2}$

In the Philippines, the agricultural industry amounts to Php 429.7 Billion, with around $50 \%$ of this consisting of crops produce. However, crop production has been experiencing a decline, further contributing to the pressure faced by farmers to increase their production. ${ }^{3}$ One of the remedies to this dilemma is the use of pesticides by farmers. An analysis of trends of the types of pesticides used in the Philippines found that the most common pesticide types were pyrethroids, organophosphates, and carbamates. ${ }^{4}$ This is an alarming finding since these pesticide types include pesticides ranging from the highest toxicity level to moderate ones. ${ }^{5}$ Acute exposure to these pesticides can lead to fatal poisoning. Even in small doses, long-term exposure also poses health risks to the farmer and those surrounding them. Long-term health effects of pesticides can range from the development of neurologic diseases, cancer, genetic diseases among the unborn, reproductive diseases, endocrine disruptions, asthma, and Parkinson's disease. ${ }^{1,6}$

The employed labor force of the agricultural industry in the Philippines comprises the second largest and composed $24.3 \%$ of the total labor force in the country. Therefore, the impact of pesticides and their health effects is an individual concern and a national one. The International Labour Organization reports that around 170,000 farmers die each year within the agricultural industry. ${ }^{7}$ They urge countries to ensure safe and healthy workplaces. However, this is not always attained, leaving workers at risk of the hazards of their occupation. ${ }^{7}$ Considering the impact of pesticides on the health of individuals, this study aimed to identify the health symptoms and physical assessment findings affecting farmers from their repeated occupational exposure to pesticides in a rural region in the Philippines.

\section{METHODS}

This research study used a cross-sectional design, and samples were drawn based on a multistage sampling of agricultural workers and farmers in 2018. The top agricultural municipalities were identified in a Muslim-dominated community in Southern Philippines. The target site was North Cotabato, labeled as the fruit basket of Mindanao, producing many tropical fruits for the entire country.

The sample was selected randomly from the identified municipalities. The samples were drawn based on a multistage sampling of farmers. Five municipalities were chosen in the first stage of sampling. The selection of respondent farmers was obtained from agricultural areas in these municipalities (Figure 1).

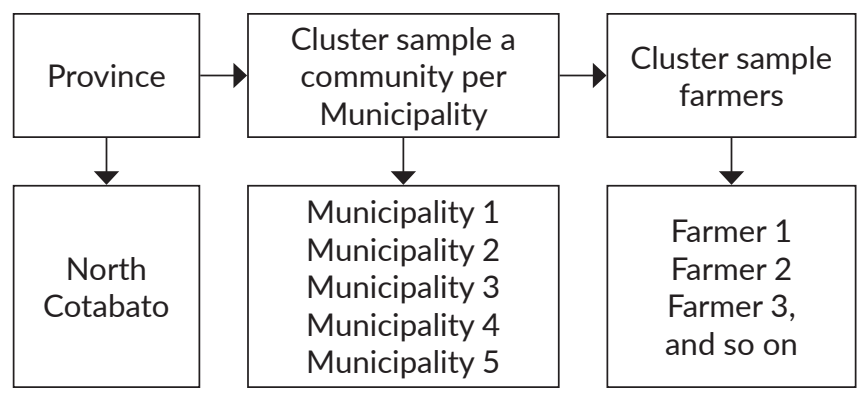

Figure 1. Multistage Sampling.

The samples were randomly selected from the identified municipalities. The sample size was obtained using Daniel's Formula for sample size computation,

$$
n=\frac{Z_{\frac{\alpha}{2}}^{2} p(1-p)}{d^{2}}
$$

where $Z_{\frac{\alpha}{2}}$ is the critical value of the normal distribution, $\alpha$ is the confidence level, $p$ is the sample proportion, and $d$ is the margin of error.

Assuming a design effect of 1 , infinite population size, confidence level at $95 \%$, and setting the sample proportion at $50 \%$ to maximize the sample size, we get a sample size of 387. The distribution of farmers in the various municipalities is shown in Table 1.

Survey questionnaires were given to 387 farmer respondents, and the collection was through a self-administered interview facilitated by a field assistant. First, a field assistant facilitated a group consisting of five to ten farmers for the survey to measure pesticide use, risk factors, and selfassessment of health. Then a physical assessment, including laboratory examinations were done by medical doctors and trained registered nurses. Finally, the samples were drawn based on a multistage sampling of farmers to represent various localities of the municipalities/communities. Out of a total of 387 farmer respondents that were surveyed using questionnaires, 267 had laboratory tests. Still, only 70 subjects underwent all tools-survey questionnaires, laboratory examination, mini-mental state examination, and physical assessment, as the others refused to participate in the other tools. Such unwillingness was respected following the ethics protocol.

The sampling frame was a list of agricultural areas in North Cotabato. When random samples of farms were selected, respondents were taken from willing participants

Table 1. Distribution of respondents by municipality $(n=387)$

\begin{tabular}{ccc} 
Municipality & Frequency & Percent \% \\
Municipality A & 135 & 34.9 \\
Municipality B & 55 & 14.2 \\
Municipality C & 68 & 17.6 \\
Municipality D & 86 & 22.2 \\
Municipality E & 43 & 11.1 \\
\hline
\end{tabular}


within the farming area. For the inclusion criteria, respondents must be a resident of North Cotabato or an immigrant who currently resides in North Cotabato, working in agriculture, majority of the time, for at least a year. Thus, people were living outside North Cotabato and people who have not worked in farming and agriculture.

The Mini-Mental State Assessment (MMSE) was also conducted on the consenting respondents to measure cognitive impairment. The MMSE was a 30-point exam where a score of 20-24 suggests mild dementia, 13-to means moderate dementia, and 12 and below indicating severe dementia. For the laboratory tests, samples from consenting respondents were tested for counts of hemoglobin mass, leukocyte, segmenter, lymphocyte, monocyte, eosinophil, basophil, red blood cells, thrombocyte, hematocrit, and butyrylcholinesterase. The counts are interpreted based on the clinically accepted normal levels for each CBC parameter, labeling abnormal or normal counts for each CBC parameter. Then physical examination was conducted by an expert primary care provider, either a doctor or a nurse. After informed consent was obtained, data was gathered regarding the physical health of the respondent. Data collected were blood pressure, heart rate, respiratory rate, head assessment, eye assessment, ear assessment, nose assessment, throat and oral cavity assessment, abdomen assessment, and skin assessment. The primary care provider determined significant findings in the evaluation who conducted the physical examination on the consenting respondent.

The data were encoded using SPSS ${ }^{\mathrm{TM}}$ 13.0. The statistics used were both descriptive and inferential. Due to the smaller sample size after physical assessment, the phi coefficient was used instead of multiple regression to see the association between certain risk factors with adverse health symptoms. This study aimed to identify the health symptoms and physical assessment findings affecting farmers from their repeated occupational exposure to pesticides in a rural region in the Philippines. This project aimed to provide a basis for the extension part of the agricultural program for the agricultural workers. The data will provide evidence of the type and nature of the extension program for the farmers and other stakeholders in the entire province of North Cotabato.

Ethics clearance was secured before the data collection from the Ethics Board of the local counterpart university to ensure confidentiality, autonomy, informed consent, and respect to subjects. Furthermore, the study was funded by the Commission on Higher Education (CHED) in the Philippines, in collaboration with the University of Southern Mindanao for the extension service program to the area. The study was approved by the Ethics Board of the said university.

\section{RESULTS}

Out of the 387 farmer respondents, $62 \%$ were male, and $33.9 \%$ were female. The majority were married $(71.1 \%)$, and the mean age was 48 years. Almost half (44.2\%) reached high school, with average year level attained of the third year (SD: \pm 0.95$) ; 22.2 \%$ reached grade school, with the mean year level attained of Grade 5 (SD: \pm 1.53 ); $19.4 \%$ reached college or tertiary level, with the mean year level attained of the second year (SD: \pm 1.12 ); $4.9 \%$ reached a vocational level, and only $1.6 \%$ reached the post-graduate level. More than half $(71.3 \%)$ were employed as an agricultural worker, $44.8 \%$ as pesticide applicators, $29.8 \%$ as a housewife but mainly still doing farming, $22.4 \%$ as growers, and $3 \%$ as pesticide distributors, The farmers used pesticide in their farms with an average of 2.3 days per week (SD: \pm 2.13 ). The mean total spraying time was 3.07 hours (SD: 14.76) per day. The average amount of pesticide used in an application was $1.33 \mathrm{~L}$ per application (SD: \pm 6.53 ). The respondents reported that they were exposed to pesticides for about 3.46 months per cropping season (SD: \pm 2.76 ), as well as from 3.34 (SD: \pm 5.92 ) cropping seasons per year (Table 1). Sixtythree percent (63\%) had spills while spraying, and $47 \%$ reported having spilled pesticides while mixing. More than half of the respondents (55\%) said they wiped sweat with a contaminated piece of fabric, and $43.2 \%$ re-entered the recently sprayed area. Moreover, $33.1 \%$ were exposed when they sprayed against the wind (Table 1). More than half $(78.6 \%)$ of the respondents said they have worked with or used pesticides, while only $9.6 \%$ said they have not worked with or used pesticides. The participants' average years of pesticide use was 17.53 years ( $\mathrm{SD} \pm 12.89)$ (Table 2).

One hundred eighty or $46.5 \%$ reported that they wore protected equipment during pesticide use. However, further investigation shows that they did not frequently use such equipment or had the adequate gear to equip themselves fully. For example, among the farmers, 108 (27.9\%) never used coveralls. Thus, a constant percentage of farmers who do not use PPEs at all was observed. In addition to this, most PPEs were used $100 \%$ of the time by less than $20 \%$ of farmers (Table 3).

When summarized into pesticide use by active ingredient, pesticides with the active ingredient of Cypermethrin (46.51\%) were the most commonly used, followed by pesticides mainly composed of Glyphosate IPA (26.36\%), Methomyl (8.53\%), and 2,4-Dichlorophenoxyacetic Acid (8.27\%). In terms of pesticide type, half of the pesticide used was pyrethroids (51.68\%), followed by organophosphates (17.05\%) and carbamates (12.66\%). In addition, pesticide use by toxicity level was also examined. It revealed that the majority of the respondents (90.1\%) use pesticides with Toxicity Level IV, followed by Toxicity Level II (24.3\%), Toxicity Level III, and Toxicity Level I (18.1\%) (Table 4).

Pesticide exposure usually occurred during agricultural activities such as spray application in the field (83.50\%), mixing (61.30\%), loading (45.20\%), field re-entry (27.60\%), and equipment care (13.30\%). The most common routes of entry from exposure to pesticides were from the respiratory tract $(72.60 \%)$, dermal route $(66.80 \%)$, and ocular route 
Table 2. Socio-demographic characteristics and other related factors among respondents in North Cotabato $(n=387)$

\begin{tabular}{|c|c|c|}
\hline & Percentage (\%) \\
\hline \multirow[t]{2}{*}{ Sex } & Male & 62 \\
\hline & Female & 33.9 \\
\hline \multirow[t]{4}{*}{ Marital status } & Single & 4.7 \\
\hline & Married & 71.1 \\
\hline & Widower & 7.0 \\
\hline & Separated & 1.3 \\
\hline \multirow[t]{5}{*}{ Educational attainment } & Gradeschool & 22.2 \\
\hline & Highschool & 44.2 \\
\hline & College & 19.4 \\
\hline & Vocational & 4.9 \\
\hline & Post-Graduate Studies & 1.6 \\
\hline \multirow{5}{*}{$\begin{array}{l}\text { Occupation } \\
\text { (multiple response) }\end{array}$} & Agricultural Worker & 71.3 \\
\hline & Pest Applicator & 44.8 \\
\hline & Housewife & 29.8 \\
\hline & Grower & 22.4 \\
\hline & & Std. Deviation \\
\hline \multicolumn{2}{|l|}{ Age } & 12.47 \\
\hline \multicolumn{2}{|l|}{ Years of pesticide use } & 12.887 \\
\hline \multicolumn{2}{|c|}{ Amount of pesticide (liters) per application } & 6.53 \\
\hline \multicolumn{2}{|c|}{ Amount of time used to prepare dilution (minutes) } & 9.03 \\
\hline \multicolumn{2}{|c|}{ Total spraying time (hours) per day } & 2.16 \\
\hline \multicolumn{2}{|c|}{ Days of pesticide use in a week } & 2.13 \\
\hline \multicolumn{2}{|c|}{ Exposure to pesticide by months per cropping season } & 2.76 \\
\hline \multicolumn{2}{|c|}{ Exposure to pesticide by cropping season per year } & 5.92 \\
\hline \multicolumn{3}{|c|}{ Percentage (\%) } \\
\hline \multicolumn{2}{|c|}{ Given instructions on how to use pesticide } & 48.6 \\
\hline \multicolumn{2}{|l|}{ Spills while spraying } & 63 \\
\hline \multicolumn{2}{|l|}{ Spills while mixing } & 47 \\
\hline \multicolumn{2}{|c|}{$\begin{array}{l}\text { Wiping sweat on the face with a contaminated } \\
\text { piece of fabric }\end{array}$} & 55 \\
\hline \multicolumn{2}{|c|}{ Re-enter recently sprayed area } & 43.2 \\
\hline \multicolumn{2}{|c|}{ Spraying against the wind } & 33.1 \\
\hline \multicolumn{2}{|l|}{ Eating at worksite } & 10.9 \\
\hline \multicolumn{2}{|l|}{ Pesticide exposure } & 78.6 \\
\hline
\end{tabular}

(through eye contact) (23.70\%). The most common route of exposure reported by respondents was through the respiratory entry of pesticides into the body, followed by dermal entry of pesticides. $45.2 \%$ of respondents reported being in contact with pesticides through respiratory exposure, while $41.6 \%$ of respondents reported being in contact with pesticides through dermal exposure.

On the other hand, most respondents used pesticides as an insecticide, followed by using pesticides as an herbicide. For example, $71.6 \%$ of the respondents use pesticides as an insecticide, while $64.1 \%$ of respondents use pesticides as herbicides (Table 5).
Table 3. Distribution of regularity of PPE use $(n=387)^{*}$

\begin{tabular}{cccc}
\multirow{2}{*}{ PPE } & \multicolumn{3}{c|}{ Regularity of PPE Use } \\
\cline { 2 - 4 } Coverall & $56(14.5)$ & $37(9.6)$ & $108(27.9)$ \\
Goggles & $44(11.4)$ & $13(3.4)$ & $146(37.7)$ \\
Face shield & $89(23)$ & $38(9.8)$ & $96(24.8)$ \\
Respirator & $46(11.9)$ & $13(3.4)$ & $135(34.9)$ \\
Apron & $35(9)$ & $11(2.8)$ & $148(38.2)$ \\
Gloves & $50(12.9)$ & $33(8.5)$ & $128(33.1)$ \\
Boots & $41(10.6)$ & $18(4.7)$ & $147(38)$ \\
\hline
\end{tabular}

*Note: Use of PPE's have missing values of $42.4 \%$ to $49.9 \%$

Table 4. Distribution of pesticides used $(n=387)^{*}$

\begin{tabular}{lrr} 
& Frequency & Percentage \\
Active Ingredient & & \\
Cypermethrin & 180 & 46.51 \\
Glyphosate IPA & 102 & 26.36 \\
Methomyl & 33 & 8.53 \\
2,4-Dichlorophenoxyacetic Acid & 32 & 8.27 \\
Chlorpyrifos & 22 & 5.68 \\
Others & 153 & 39.53 \\
\hline Pesticide Type & & \\
Pyrethroid & 200 & 51.68 \\
Organophosphate & 66 & 17.05 \\
Carbamate & 49 & 12.66 \\
Chlorinated Phenoxy & 32 & 8.27 \\
Others & 94 & 24.29 \\
\hline Toxicity Level & & \\
Toxicity Level I & 70 & 18.1 \\
Toxicity Level II & 94 & 24.3 \\
Toxicity Level III & 75 & 19.4 \\
Toxicity Level IV & 352 & 90.1 \\
\hline
\end{tabular}

\section{Health Symptoms among Farmers}

Approximately thirty-four percent (33.9\%) of the farmers complained of being sick due to their work for the last 12 months preceding the study. Of those who got ill, more than half of the respondents, $53.2 \%$, did not receive any medical attention, and only $12.1 \%$ received some medical attention. Occupational exposure was more predominant (16.8\%) than accidental exposure (12.1\%).

In terms of the general symptoms reported by the respondents, the most prevalent were muscle pains (70.50\%), followed by weakness (65.10\%), and easy fatigability (40.20\%). The most commonly experienced eye, ear, nose, throat (EENT) symptoms as well were eye pain $(54.70 \%)$, eye redness (54.70\%), and blurring of vision (54.20\%). Neurologic symptoms were also taken, and a headache was the most common, with $79.4 \%$ experiencing this. This was followed by experiencing dizziness (50.20\%) and vertigo (23.40\%) among respondents. The most commonly expe- 
Table 5. Distribution of occupational activities at time of exposure, route of exposure and type of pesticide exposure $(n=387)$

\begin{tabular}{lrc}
\multicolumn{1}{c}{ Exposure Factors } & Frequency & Percentage \\
\hline Occupation activities & & \\
Application in field & 233 & 83.5 \\
Mixing & 171 & 61.3 \\
Loading & 126 & 45.2 \\
Field re-entry & 77 & 27.6 \\
Equipment care & 37 & 13.3 \\
Transportation & 38 & 13.6 \\
Bystander & 20 & 7.2 \\
Public health & 3 & 1.1 \\
Others & 5 & 1.8 \\
\hline Route and type of pesticide exposure & 19 & \\
Oral route & 175 & 4.9 \\
Respiratory route & 57 & 14.7 \\
Ocular route & 161 & 41.6 \\
Dermal route & & \\
\hline Route and type of pesticide exposure & 277 & 71.6 \\
Insecticide as pesticide type & 184 & 47.5 \\
Fungicide as pesticide & 17 & 4.4 \\
Tick control as pesticide & 248 & 64.1 \\
Herbicide as pesticide & 99 & 25.6 \\
Rodenticide as pesticide & & 5.4 \\
Nematocide as pesticide & & \\
\hline
\end{tabular}

*Multiple response

rienced gastrointestinal symptoms were nausea (33.80\%), vomiting (32.40\%), and salivation (19.40\%). In terms of respiratory symptoms experienced by the farmers, the most prevalent reports were coughing (87.40\%), difficulty of breathing (23\%), and breathlessness (21.30\%). Cardiovascular symptoms commonly experienced were also chest pain (62.90\%), palpitations (46.10\%), and calf pain (28.70\%). Symptoms relating to the integumentary system were also asked from the respondents. The majority experienced nail changes (39.60\%), sweating (31.40\%), and jaundice (30.20\%) (Table 6).

\section{Mini-Mental Status Examination}

$93.95 \%$ of the respondents have normal cognitive function based on their MMSE scores. On the other hand, $3.6 \%$ have been found to have a mild cognitive impairment, $0.8 \%$ have a moderate cognitive impairment, and $0.4 \%$ have severe cognitive impairment. $1.2 \%$ have been found to have profound cognitive impairment (Table 7).

\section{Laboratory Findings}

The significant health findings were determined by the physician who conducted the physical examination on the consenting respondents. On the other hand, $\mathrm{CBC}$
Table 6. Distribution of symptoms reported by farmers according to body area

\section{Symptoms}

Frequency Percentage

General symptoms

$\begin{array}{lrr}\text { Muscle pain } & 184 & 70.5 \\ \text { Weakness } & 170 & 65.1 \\ \text { Easy fatigability } & 105 & 40.2 \\ \text { Loss of appetite } & 92 & 35.2 \\ \text { Fever } & 80 & 30.7\end{array}$

Eye, ear, nose, throat symptoms

Eye pain $\quad 129 \quad 54.7$

Eye redness 129

54.7

Blurring of vision $\quad 128$

54.2

$\begin{array}{lll}\text { Eye tearing } & 116 & 49.2\end{array}$

Eye itchiness

$108 \quad 45.8$

\begin{tabular}{lrl}
\hline Neurologic symptoms & & \\
Headache & 166 & 79.4 \\
Dizziness & 105 & 50.2 \\
Vertigo & 49 & 23.4 \\
Confusion & 47 & 22.5 \\
Drowsiness & 46 & 22.0
\end{tabular}

\begin{tabular}{lcc}
\hline Gastrointestinal symptoms & & \\
Nausea & 47 & 33.8 \\
Vomiting & 27 & 32.4 \\
Salivation & 24 & 19.4 \\
Gastro-intestinal burn & 23 & 17.3 \\
Difficulty swallowing & & \\
\hline Respiratory symptoms & 160 & \\
Coughing & 42 & 23.4 \\
Difficulty breathing & 39 & 21.3 \\
Breathlessness & 34 & 18.6 \\
Pulmonary secretions & 32 & 17.5 \\
Pain on deep breathing & & \\
Cardiovascular symptoms & 105 & 62.9 \\
Chest pain & 77 & 46.1 \\
Palpitations & 48 & 28.7 \\
Calf pain & 23 & 13.8 \\
Pillow orthopnea & 23 & 13.8 \\
Arrhythmias & & \\
\hline Integumentary symptoms & 67 & 39.6 \\
Nail changes & 53 & 31.4 \\
Sweating & 51 & 30.2 \\
Jaundice & 46 & 27.2 \\
Skin rashes & & 24.9 \\
Skin itchiness & & \\
\hline
\end{tabular}

${ }^{*}$ Multiple response 
Table 7. Distribution of mini-mental status examination results among farmers in the Philippines $(n=248)$

\begin{tabular}{ccc} 
Score & Frequency (\%) & Interpretation \\
24 to 30 & $233(93.95)$ & Normal \\
20 to 23 & $9(3.6)$ & Mild Cognitive Impairment \\
10 to 19 & $2(0.8)$ & Moderate Cognitive Impairment \\
1 to 9 & $1(0.4)$ & Severe Cognitive Impairment \\
0 & $3(1.2)$ & Profound Cognitive Impairment \\
\hline
\end{tabular}

Table 8. Distribution of blood parameter result among respondents $(n=267)$

\begin{tabular}{lcc} 
Blood parameters & Normal Range & Percent Abnormal \\
\hline lemoglobin Mass & $140-160 \mathrm{~g} / \mathrm{L}$ & 44.7 \\
eukocyte & $5-10 \times 10^{9} \mathrm{~g} / \mathrm{L}$ & 18.8 \\
egmenter & $0.50-0.70$ & 27.0 \\
Lymphocyte & $0.23-0.35$ & 55.9 \\
Monocyte & $0.03-0.06$ & 47.2 \\
osinophil & $0.02-0.04$ & 62.4 \\
Basophil & $0.00-0.01$ & 0 \\
Red Blood Cell & $4.5-6.0 \times 10^{12} / \mathrm{L}$ & 31 \\
Thrombocyte & $150-350 \times 10^{9} / \mathrm{L}$ & 4.7 \\
Hematocrit & $0.40-0.47$ & 29.5 \\
Butyrylcholinesterase & $5400-13200 \mathrm{U} / \mathrm{l}$ & 10.0
\end{tabular}

parameter counts were interpreted based on clinically accepted normal levels. The distribution of respondents based on their laboratory results is presented in Table 8. The laboratory findings showed more abnormal results for both lymphocytes (55.9\%) and eosinophils (62.4\%). The abnormal results for lymphocytes showed that $92.9 \%$ had high abnormal results. Ten (10) percent had abnormal butyrylcholinesterase.

\section{Statistical Associations}

Only a maximum of 70 farmer respondents gave consent and participated in all tools: the survey, laboratory examination, and physical assessment phases of the study. The subject participant could opt to proceed or not with the rest of the tools used in the study. Hence, it is not recommended to perform logistic regression. ${ }^{8}$ The recommended sample size for performing logistic regression according to Bujang et al. is at least a minimum of $100+50 \mathrm{i}$, where $\mathrm{i}$ is the number of independent variables in the final model. ${ }^{8}$ Instead, the "Phi Coefficient" or the "Mean Square Contingency Coefficient" was used to measure association since most associations were between two dichotomous variables. ${ }^{9}$

Significant head findings were found to be associated with the following-respiratory exposure to pesticides (weak association), insecticide exposure (moderate association), and abnormal thrombocyte level (very strong association). Abnormal thrombocyte level was again found to be strongly associated with head alopecia, as well as icteric sclera.

Table 9. Associations Between Exposure Variables and Physical Assessment Findings using Phi Coefficient ( $n=70)$

\begin{tabular}{|c|c|c|c|}
\hline Physical health assessment & Risk Factors & Phi Coefficient & P-value \\
\hline \multirow[t]{3}{*}{ Significant head findings } & Respiratory exposure to pesticide & 0.238 & 0.041 \\
\hline & Insecticide exposure & 0.344 & 0.002 \\
\hline & Abnormal thrombocyte level & 0.707 & $<0.0001$ \\
\hline \multirow[t]{3}{*}{ Head alopecia } & Insecticide exposure & 0.283 & 0.014 \\
\hline & Abnormal leukocyte level & 0.268 & 0.02 \\
\hline & Abnormal thrombocyte level & 0.707 & $<0.0001$ \\
\hline \multirow[t]{5}{*}{ Significant cardiovascular findings } & Dermal exposure to pesticide & 0.281 & 0.014 \\
\hline & Nematocide exposure & 0.342 & 0.002 \\
\hline & Fungicide exposure & 0.260 & 0.024 \\
\hline & Rodenticide exposure & 0.339 & 0.003 \\
\hline & Abnormal segmenter level & 0.273 & 0.037 \\
\hline Significant throat/oral cavity findings & Ocular exposure to pesticide & 0.283 & 0.013 \\
\hline Significant lung findings & Nematocide exposure & 0.246 & 0.034 \\
\hline \multirow[t]{5}{*}{ Significant eye findings } & Nematocide exposure & 0.402 & 0.0002 \\
\hline & Rodenticide exposure & 0.265 & 0.021 \\
\hline & Organophosphate exposure & 0.350 & 0.013 \\
\hline & Pyrethroid exposure & 0.336 & 0.018 \\
\hline & Abnormal thrombocyte level & 0.483 & 0.007 \\
\hline Icteric sclera & Abnormal thrombocyte level & 0.707 & $<0.0001$ \\
\hline \multirow[t]{2}{*}{ Ophthalmic discharge } & Thrombocyte & 0.489 & 0.007 \\
\hline & Butyrylcholinesterase & 0.326 & 0.014 \\
\hline
\end{tabular}


Strong positive relationships were found for thrombocyte and ophthalmic discharge, thrombocyte, and significant eye findings, as well as Nematocide and significant nose findings. Thrombocyte and other blood test results were categorized as "normal" and "abnormal." For the phi coefficient, this classification was used- weak association for phi coefficients of 0.2 to 0.29 ; moderate for $0.3-0.39$; strong association for 0.4-0.7; and very strong association for $>0.7$ (Table 9).

\section{DISCUSSION}

In this study, males consisted of more than half (62\%) of the respondents among farmers. This reflects the Philippine Statistics Authority data on the gender distribution of workers in the agricultural industry. A more significant number of males (7.93 million) than females (2.33 million) were found to work within the farming sector in the Philippines (PSA, 2018). The farmers involved also exhibited an average spraying time of pesticide of 3.07 hours $(\mathrm{SD} \pm 2.16)$. This was consistent with a study done in Ghana among yam farmers who claimed to spend around 2 to 4 hours spraying pesticides on the farm. However, they would only need to do this twice a year. Despite only using pesticides around two times a year, their study already observed that the exposed farmers exhibited health outcomes linked to pesticide exposure. ${ }^{10}$ In this Philippine-based study, the farmers were found to use pesticides for an average of 2.31 days $( \pm 2.13 \mathrm{SD}$ ) per week for an average of 3.46 months $( \pm 2.76 \mathrm{SD})$ per cropping season. There were an average of $3.34( \pm 5.92 \mathrm{SD})$ cropping seasons per year. This finding showed that farmers in the study were exposed for longer durations than the farmers from Ghana who already experienced adverse health outcomes from their amount of pesticide use. ${ }^{10}$ It should also be noted that $29.8 \%$ of the respondents were housewives, indicating that not only those directly involved in the farming occupation are at risk for exposure to pesticides and their harmful effects on the body. Various studies have contributed to the growing evidence on the pesticide exposure faced by household members, especially farmers' wives. ${ }^{11-14}$

The most commonly observed pesticides used by farmers in this study were Cypermethrin (46.51\%), Glyphosate IPA (26.36\%), Methomyl, and 2,4-Dichlorophenoxyacetic Acid (8.27\%). In terms of pesticide types, commonly used by farmers were pyrethroids (51.68\%), organophosphates (17.05\%), and carbamates (12.66\%). This pattern in pesticide use was also commonly observed among other studies in the Philippines, ${ }^{4,15-17}$ In addition to this, it is also common practice among farmers to use one pesticide type and turn these into a cocktail mixture. ${ }^{15,17-19}$ Farmers do this due to their belief that mixing pesticides will have a synergistic effect, increasing their effectiveness among the produce. ${ }^{19}$ However, there is no scientific basis for this, and studies have found that the mixture of pesticides to produce a cocktail holds more significant health risks for users. ${ }^{18-20}$ A study conducted in Egypt by Hassanin et al. observed explicitly that those exposed to a mixture of more than two pesticide types exhibited a more significant increase in creatinine levels than those who were not. ${ }^{20}$

It is crucial to identify what parts of pesticide use are farmers exposed to these chemicals. The occupational activities involving pesticides engaged in by most farmers in this study were application in the field (83.50\%), mixing pesticides (61.30\%), loading pesticides (45.2\%), re-entering a recently sprayed area (27.6\%), and taking care of equipment used for application (13.3\%). However, the risk for pesticide exposure is always present as long as the farmer is handling or using this in any way. Pesticides enter the body through the dermal, oral, and respiratory routes, and it is through these, the body comes into contact with these chemicals. A study found that dermal exposure can occur in any stage of pesticide usage, beginning from preparation to application and cleaning the equipment. ${ }^{21}$ Another study in Ethiopia illustrated how pesticides could enter through the respiratory route as supported by the association made with exposure to respiratory health symptoms among farmers. ${ }^{22}$

The sample population reported multiple symptoms. In terms of general symptoms, the most common were muscle pain (70.50\%), weakness (65.10\%), easy fatigability (40.20\%), loss of appetite (35.20\%), and fever (30.70\%). Similar symptoms were reported in other studies as well. ${ }^{17,20,23,24}$ Symptoms experienced in the eye, ear, nose, and throat were also asked from respondents. The most common were eye pain $(54.70 \%)$, eye redness $(54.70 \%)$, blurring of vision (54.20\%), eye tearing (49.20\%), and eye itchiness (45.80\%). The occurrence of these symptoms may have stemmed from exposure brought about by pesticide use in any form. In addition to this, an experiment conducted among pesticideexposed albino mice exhibited ocular compromise compared to the controls. Changes included redness and irritation of the eyes, tearing of the eyes, corneal abrasions, decreased viable cells, increased cell death, increased mitochondrial toxicity, increased lysosomal toxicity, increased cytotoxicity, structural damages to tissue, increased injured cells, decreased ocular cell function. These were present among long-term exposed mice compared to a control group who were not exposed..$^{25}$ The eyes can also be affected by pesticide exposure. The vulnerabilities may have brought this about to the ocular tissue caused by exposure from longterm pesticide use, as similarly observed among pesticideexposed albino mice. ${ }^{26}$ Neck mass and lymphadenopathy can also result from pesticide exposure. Similar findings were also observed among pesticide users in the Philippines and other countries. ${ }^{27,28}$ In addition to this, a study in Iran observed that the higher an individual's exposure to pesticides, the higher the odds of developing head and neck cancers. They found that the risk existed among exposure to organochlorine pesticides, most likely due to its potential to cause genotoxicity and other cellular damages to the body. ${ }^{29}$

Neurologic symptoms were also present among the respondents of the study. The commonly experienced 
symptoms were headache (79.40\%), dizziness (50.20\%), vertigo (23.40\%), confusion (22.50\%), and drowsiness (22\%). However, the respondents also reported experiencing local and general fasciculation (18.70\%; 8.60\%), tremors (14.40\%), paresthesia (13.90\%), loss of consciousness (12.40\%), and ataxia (8.60\%). These findings are consistent with other studies as well. ${ }^{10,17,23,24,30}$ The mini-mental state exam was done to test if the respondents showed signs of cognitive impairment. The results revealed that most respondents (93.95\%) showed normal cognitive function, while 6.05\% had some level of cognitive impairment. A study among exposed farmers in Korea also observed an association between increased pesticide exposure and cognitive decline. However, this association was no longer statistically significant after confounders were adjusted. ${ }^{31}$ Contrary to this, another study among the elderly found decreasing cognitive performance scores as age and pesticide exposure increased. There was also evidence to believe that cognitive performance generally decreased among all age groups for those with increased exposure to p,p'-dichlorodiphenyltrichloroethane, and p,p'dichlorodiphenyldichloroethylene- types of organochlorine pesticides. ${ }^{32}$ The cognitive alterations brought about by pesticides do not only affect those presently exposed but can extend to unborn offspring as well. Studies have observed that increases in maternal exposure to pesticides resulted in cognitive ability and IQ declines among their schoolage children. ${ }^{33,34}$ In particular, pesticides caused significant neurologic effects on the body and were even weaponized for this reason. Organophosphates are known to affect the nervous system by inducing lipid peroxidation, neurodegeneration, and compromising neuronal processes. ${ }^{35}$

Another set of symptoms extracted from the respondents were those relating to the gastrointestinal tract. Common symptoms reported were nausea (33.8\%), vomiting (32.4\%), salivation (19.4\%), gastro-intestinal burn (17.3\%), and difficulty swallowing (16.5\%). Similar symptoms were also reported in other studies as well. ${ }^{16,23,24,36}$ Another route of entry into the body for pesticides is through ingestion, which could occur through directly consuming the chemical or consuming contaminated food. An in-silico evaluation of pesticides showed that multiple pesticides registered with high intestinal absorption. The pesticide types with high intestine absorption and permeability were the following: triazines, carbamates, organophosphorus, and pyrethroid. Organochlorines exhibited the lowest percentage of permeability. However, it was still $40 \%$ permeable for intestinal absorption. ${ }^{37}$ It should also be noted that ingestion of pesticides does not only occur among those presently exposed but can also carry on to infants. A study in India analyzed mothers' colostrum and mature milk and observed that a considerable amount was contaminated with pesticides such as ethion, dimethoate, and chlorpyrifos. This poses a significant risk for infants since the milk of their mother is ingested along with the traces of pesticides. ${ }^{38}$
The respondents of this study also commonly reported respiratory symptoms and represented another route of pesticide exposure - inhalation. The symptoms reported were coughing (87.4\%), difficulty breathing (23\%), breathlessness (21.3\%),pulmonary secretions (18.6\%), pain on deep breathing (17.5\%). These symptoms were also consistent with other studies whose respondents also complained of respiratory symptoms. ${ }^{16,17,22,24,39}$ In addition to these symptoms, studies have also reported declines in lung function parameters among pesticide-exposed individuals. ${ }^{22,24} \mathrm{~A}$ study done in Canada by $\mathrm{Ye}$ et al. analyzed the plasma concentration of certain banned organochlorine pesticides among individuals and found that those with higher levels exhibited lower lung function parameters, such as $\mathrm{FEV}_{1}$ and $\mathrm{FVC} .{ }^{40}$

Aside from respiratory symptoms, cardiovascular symptoms were also reported among the respondents. The most common symptoms reported were chest pain (62.9\%), palpitations (46.1\%), calf pain (28.7\%), pillow orthopnea (13.8\%), and arrhythmias (13.8\%). These were consistent with the reported symptoms from a review of studies conducted by Sekhotha, Monyeki, and Sibuyi in which they reported that certain pesticides such as ethylene dibromide, mancozeb, Ziram, dichlorodiphenyltrichloroethane, 2,4,5-trichlorophenoxyacetic acid, chlorpyrifos, coumaphos, and carbofuran, among others were found to be statistically associated with the occurrence of certain cardiovascular diseases. In addition to this, a few of the pesticides associated with cardiovascular diseases were known to be acetylcholinesterase inhibitors, which can cause cardiotoxicity ${ }^{41}$ Another study also observed that glyphosate herbicides resulted in abnormal heart function parameters and may have caused death in some. ${ }^{42}$ Studies also observed abnormalities in certain cardiovascular biomarkers of individuals exposed to pesticides; as well as increased odds of experiencing various cardiovascular ailments, such as coronary heart disease, cerebrovascular disease, atrial fibrillation, and heart failure. ${ }^{43,44}$

Aside from the symptoms experienced by the respondents, blood samples were taken as well, and blood parameters were found to be abnormal for some farmers. Abnormalities in blood parameters were observed among participants in other studies. ${ }^{16,20,30,45} \mathrm{~A}$ study done by Shearer et al. observed that pesticide-exposed individuals exhibited increased immature granulocyte count and decreased $\mathrm{RBC}$ count and hemoglobin levels in comparison to their off-season results. ${ }^{45}$ The researchers explained that this occurred due to an inflammatory response that triggered an increase in the immature granulocyte count. However, these failed to reach maturity, explaining the decrease in $\mathrm{RBC}$ count and hemoglobin levels. This mechanism may also be linked to cancer development by reducing the body's anti-tumor mechanism as immature granulocytes increased. Certain pesticides, such as permethrin, were also observed to cause injury and death of red blood cells in the body, further contributing to the observed decrease in 
RBC count and hemoglobin levels. ${ }^{45}$ As for the increased lymphocyte and eosinophil, the study conducted by Hassanin et al. observed that their sample's neutrophil levels decreased while eosinophil levels increased. ${ }^{20}$ It is hypothesized that short-term exposure's impact was on the already developed peripheral blood components, while long-term exposure's effect was directed towards the bone marrow. This would explain why an increase in white blood cells was present among those with long-term exposure. ${ }^{30}$ This observation may applied to the present study, and the average years of pesticide use by the participants were 17.53 $(\mathrm{SD} \pm 12.89)$ years.

Butyrylcholinesterase is a type of non-specific plasma cholinesterase commonly used as one of the indicators for low-level chronic exposure to organophosphate and carbamate pesticides. Exposure to these pesticides can inhibit acetylcholinesterase and cause significant neurotoxic and cardio-toxic effects. ${ }^{18,41}$ However, as mentioned earlier, the limitation of this study was its lack of a comparator for the laboratory measures obtained. Especially since butyrylcholinesterase depression was established when a $20 \%$ reduction was observed, even if measurements fell within normal levels, a reduction cannot be ruled out due to the lack of baseline or post-exposure. ${ }^{46}$ Reduction in butyrylcholinesterase was observed by various other studies whose participants were exposed to pesticides. ${ }^{16,18,23} \mathrm{~A}$ study conducted in the Philippines by Lu specifically observed a $50.80 \%$ reduction in $\mathrm{RBC}$ cholinesterase among their participants. ${ }^{16}$ In this study in North Cotabato, $10 \%$ had abnormal butyrylcholinesterase levels. ${ }^{16}$

Certain laboratory parameters were also found to be significantly associated with the occurrence of physical assessment findings. Abnormal thrombocyte level was again found to be strongly associated with head alopecia, as well as icteric sclera. Strong positive relationships were found for thrombocyte and ophthalmic discharge, thrombocyte, and significant eye findings, as well as nematocide and significant nose findings. It was previously mentioned that pesticides could enter the body and cause short-term and long-term effects. Included as these effects were the damages it caused to the blood components of the body. ${ }^{30}$ This would explain why certain lab values were associated with the occurrence of physical assessment findings. It does not mean there was a direct association. However, they may serve as a proxy for the occurrence of acute pesticide poisoning.

Pesticides are also known to cause oxidative stress through an imbalance between reactive oxidative species and antioxidants. This could lead to damage and injury to the DNA, affecting the function and communication of cells, which ultimately lead to the development of diseases when the individual is repeatedly exposed to this. ${ }^{47}$ Butyrylcholinesterase levels were also found to be associated with the occurrence of ophthalmic discharge. Again, this does not mean a direct association between the two variables; however, depressed butyrylcholinesterase levels are usually a sign of organophosphate and carbamate exposure which are also known to be associated with a wide variety of symptoms. ${ }^{18,48}$ Cholinesterase inhibition was also found to cause a series of ocular symptoms from the increased eye injury susceptibility that it causes. As mentioned previously, after long-term exposure to cholinesterase inhibiting chemicals, albino mice began presenting with an eye injury and tearing as compared to the mice who were not exposed. ${ }^{25}$

\section{CONCLUSION}

The evidence supporting pesticide's harmful effects continues to grow, especially among developed countries where the impact is much graver. This study translates pesticide's health impact by identifying the common symptoms experienced by farmers and concerning physical assessment findings. The study found that the participants in this study suffer from a range of symptoms plaguing the general health, eye, ears, nose, and throat region, neurological system, gastrointestinal system, respiratory system, cardiovascular system, and the integumentary system. The laboratory parameters of the participants also exhibited abnormalities indicative of significant exposure and possible poisoning from pesticides. The associations found were also supportive of the impact that pesticides pose to the body. Limitations of the study included the lack of a control or baseline group to compare the findings of the laboratory parameter levels. It is recommended that future researchers consider this as they may provide a clearer picture of the actual impact of pesticides on the health of agricultural communities.

The findings of this study also stress the need for local government units and concerned organizations to take a proactive stand against improper and unsafe use of pesticides as the health of those who run the country's biggest economic sector proves to be at risk.

\section{Statement of Authorship}

Both authors participated in the data collection and analysis and approved the final version submitted.

\section{Author Disclosure}

Both authors declared no conflicts of interest.

\section{Funding Source}

This study was funded by the Commission on Higher Education - Philippines.

\section{REFERENCES}

1. Bolognesi C, Merlo FD. Pesticides: Human Health Effects. In: Nriagu JO, editor. Encyclopedia of Environmental Health. 1st ed. Encyclopedia of Environmental Health. London: Elsevier Science; 2011. p. 438-53.

2. Oyekale AS. Cocoa Farmers' Compliance with Safety Precautions in Spraying Agrochemicals and Use of Personal Protective Equipment (PPE) in Cameroon. Int J Environ Res Public Health. 2018 Feb 13;15(2):327. 
3. Philippine Statistics Authority. Performance of Philippine Agriculture January-March 2019 [Internet]. Philippine Statistics Authority. 2019 [cited 2021 Apr]. Available from: https://psa.gov.ph/content/ performance-philippine-agriculture-january-march-2019.

4. Lu JL. Analysis of Trends of the Types of Pesticide Used, Residues and Related Factors among Farmers in the Largest Vegetable Producing Area in the Philippines. J Rural Med. 2010;5(2):184-9.

5. World Health Organization \& International Programme on Chemical Safety. The WHO Recommended Classification of Pesticides by Hazard and Guidelines to Classification 2009 [Internet]. Geneva: World Health Organization; 2010 [cited 2021 Apr]. Available from: https://apps.who.int/iris/handle/10665/44271

6. Kim KH, Kabir E, Jahan SA. Exposure to Pesticides and the Associated Human Health Effects. Sci Total Environ. 2017 Jan 1;575:525-535.

7. International Labour Organization [Internet]. Geneva: International Labour Organization; c1991-2021 [cited 2021 Apr]. Agriculture: a hazardous work. Available from: https://www.ilo.org/safework/ areasofwork/hazardous-work/WCMS_110188/lang--en/index.htm.

8. Bujang MA, Sa'at N, Sidik TMITAB, Joo LC. Sample Size Guidelines for Logistic Regression from Observational Studies with Large Population: Emphasis on the Accuracy Between Statistics and Parameters Based on Real Life Clinical Data. Malays J Med Sci. 2018 Jul; 25(4):122-30.

9. Larntz K. Small-Sample Comparisons of Exact Levels for ChiSquared Goodness-of-Fit Statistics. J Am Stat Assoc. 1978 Jun; 73(362):253-63.

10. Wumbei A, Houbraken M, Spanoghe P. Pesticides Use and Exposure Among Yam Farmers in the Nanumba Traditional Area of Ghana. Environ Monit Assess. 2019 Apr 25;191(5):307.

11. Carreón T, Butler MA, Ruder AM, Waters MA, Davis-King KE, Calvert GM, et al. Gliomas and Farm Pesticide Exposure in Women: The Upper Midwest Health Study. Environ Health Perspect. 2005 May;113(5):546-51.

12. Deziel NC, Friesen MC, Hoppin JA, Hines CJ, Thomas K, Freeman LE. A Review of Nonoccupational Pathways for Pesticide Exposure in Women Living in Agricultural Areas. Environ Health Perspect. 2015 Jun;123(6):515-24. Epub 2015 Jan 30.

13. Lu JL. Gender analysis of women in the Philippine Agriculture and Their Occupational Issues. Journal of International Women's Studies. 2010;11(4):73-82.

14. Yanco JJ. Silent Invaders: Pesticides, Livelihoods, and Women's Health. Int J Afri Hist Stud. 2005. 38(1): 153-5.

15. Lu JL. Pesticide-related safety risks among vegetable farmers: A Cross Sectional Study. Ergonomics SA. 2015;27(2): 50-63.

16. Lu JL. Ergonomic and health assessment of farmers' multi-pesticide exposure. Ergonomics SA. 2017;29(1), 20-35.

17. Perez IC, Gooc CM, Cabili JR, Rico MJ, Ebasan MS, Zaragoza MJ, et al. Pesticide use among farmers in Mindanao, Southern Philippines. AES Bioflux. 2015; 7(1):90-108.

18. Krenz JE, Hofmann JN, Smith TR, Cunningham RN, Fenske RA, Simpson CD, et al. Determinants of Butyrylcholinesterase Inhibition Among Agricultural Pesticide Handlers in Washington State: An Update. Ann Occup Hyg. 2015 Jan;59(1):25-40. Epub 2014 Sep 26.

19. Manyilizu W, Mdegela R, Helleve A, Skjerve E, Kazwala R, Nonga, $\mathrm{H}$, et al. Self-reported Symptoms and Pesticide Use Among Farm Workers in Arusha, Northern Tanzania: A Cross-sectional Study. Toxics. 2017;5(4):4

20. Hassanin NM, Awad OM, El-Fiki S, Abou-Shanab RA, AbouShanab AR, Amer RA. Association between exposure to pesticides and disorder on hematological parameters and kidney function in male agricultural workers. Environmental Science and Pollution Research. 2018;25(31):30802-30807.

21. Fabian C, Binder C. Dermal Exposure Assessment to Pesticides in Farming Systems in Developing Countries: Comparison of Models. Int J Environ Res Publ Health. 2015;12(5):4670-4696

22. Negatu B, Kromhout H, Mekonnen Y, Vermeulen R. Occupational Pesticide Exposure and Respiratory Health: A Large-scale Crosssectional Study in Three Commercial Farming Systems in Ethiopia. Thorax. 2017. 72(6), 498-9
23. Lermen J, Bernieri T, Rodrigues IS, Suyenaga ES, Ardenghi PG. Pesticide Exposure and Health Conditions Among Orange Growers in Southern Brazil. J Environ Sci Health B. 2018 Apr;53(4):215-21

24. Mathew P, Jose A, Alex RG, Mohan VR. Chronic Pesticide Exposure: Health Effects Among Pesticide Sprayers in Southern India. Indian J Occup Environ Med. 2015;19(2):95.

25. Sanyal S, Das P, Law S. Effect of Chronic Pesticide Exposure on Murine Cornea: A Histopathological, Cytological and Flow Cytometric Approach to Study Ocular Damage by Xenobiotics. Cell Biol Toxicol. 2016;32(1):7-22.

26. Pham H, Lingao MD, Ganesh A, Capasso JE, Keep R, Sadagopan $\mathrm{KA}$, et al. Organophosphate Retinopathy. Oman J Ophthalmol. 2016;9(1):49-51

27. Sapbamrer R, Nata S. Health Symptoms Related to Pesticide Exposure and Agricultural Tasks Among Rice Farmers From Northern Thailand. Environ Health Prev Med. 2014;19(1):12-20.

28. Sonchieu J, Akono EN, Ngwamitang CT, Ngassoum BM. Heath Risk Among Pesticide Sellers in Bamenda (Cameroon) and Peripheral Areas. Environ Sci Pollut Res Int. 2018;25(10),9454-60.

29. Amizadeh M, Safari-Kamalabadi M, Askari-Saryazdi G, Amizadeh M, Reihani-Kermani, H. Pesticide Exposure and Head and Neck Cancers: A Case-Control Study in an Agricultural Region. Iran J Otorhinolaryngol. 2017;29(94):275-85.

30. Hu R, Huang X, Huang J, Li Y, Zhang C, Yin Y, et al. Long and Short-term Health Effects of Pesticide Exposure: A Cohort Study From China. PLoS One. 2015;10(6):e0128766.

31. Kim JY, Park S, Kim SK, Kim CS, Kim TH, et al. Pesticide Exposure and Cognitive Decline in a Rural South Korean Population. PLoS One. 2019;14(3):e0216310.

32. Kim S-A, Lee Y-M, Lee H-W, Jacobs DR Jr, Lee D-H. Greater Cognitive Decline with Aging Among Elders with High Serum Concentrations of Organochlorine Pesticides. PLoS ONE. 2015; 10(6):e0130623.

33. Gunier RB, Bradman A, Harley KG, Kogut K, Eskenazi B. Prenatal Residential Proximity to Agricultural Pesticide Use and IQ in 7-yearold Children. Environ Health Perspect. 2017 May;125(5):057002.

34. Jusko TA, van den Dries MA, Pronk A, Shaw PA, Guxens M, Spaan $\mathrm{S}$, et al. Organophosphate Pesticide Metabolite Concentrations in Urine during Pregnancy and Offspring Nonverbal IQ at Age 6 Years. Environ Health Perspect. 2019 Jan;127(1):17007. Erratum in: Environ Health Perspect. 2019 May;127(5):59002. PMID: 30688513; PMCID: PMC6381821.

35. Terry AV Jr. Functional Consequences of Repeated Organophosphate Exposure: Potential Non-cholinergic Mechanisms. Pharmacol Ther. 2012 Jun;134(3):355-65. Epub 2012 Mar 20.

36. Fareed M, Kesavachandran CN, Bihari V, Kamal R, Kuddus M. Oxidative Stress and Cholinesterase Depression Among Farmworkers Occupationally Exposed to Pesticides in India. JEB. 2017;38(2), 305-11.

37. Chedik L, Mias-Lucquin D, Bruyere A, Fardel O. In Silico Prediction for Intestinal Absorption and Brain Penetration of Chemical Pesticides in Humans. Int J Environ Res Public Health. 2017 Jun 30;14(7):708.

38. Srivastava S, Narvi SS, Prasad SC. Levels of Select Organophosphates in Human Colostrum and Mature Milk Samples in Rural Region of Faizabad District, Uttar Pradesh, India. Hum Exp Toxicol. 2011 Oct;30(10):1458-63.

39. Cherry N, Beach J, Senthilselvan A, Burstyn I. Pesticide Use and Asthma in Alberta Grain Farmers. Int J Environ Res Public Health. 2018 Mar 15;15(3):526.

40. Ye M, Beach J, Martin JW, Senthilselvan A. Association Between Lung Function in Adults and Plasma DDT and DDE Levels: results from the Canadian Health Measures Survey. Environ Health Perspect. 2015 May;123(5):422-7.

41. Sekhotha MM, Monyeki KD, Sibuyi ME. Exposure to Agrochemicals and Cardiovascular Disease: A Review. Int J Environ Res Public Health. 2016 Feb 18;13(2):229.

42. Gress S, Lemoine S, Séralini GE, Puddu PE. Glyphosate-based Herbicides Potently Affect Cardiovascular System in Mammals: Review of the Literature. Cardiovasc Toxicol. 2015 Apr;15(2):117-26. 
43. Kongtip P, Nankongnab N, Mahaboonpeeti R, Bootsikeaw S, Batsungnoen K, Hanchenlaksh $\mathrm{C}$, et al. Differences among Thai Agricultural Workers' Health, Working Conditions, and Pesticide Use by Farm Type. Ann Work Expo Health. 2018 Feb;62(2):167-81.

44. Bulka CM, Daviglus ML, Persky VW, Durazo-Arvizu RA, Lash JP, Elfassy T, et al. Association of Occupational Exposures with Cardiovascular Disease Among US Hispanics/Latinos. Heart. 2019 Mar;105(6):439-48.

45. Shearer JJ, Beane Freeman LE, Liu D, Andreotti G, Hamilton J, Happel $\mathrm{J}$, et al. Longitudinal Investigation of Haematological Alterations Among Permethrin-exposed Pesticide Applicators in the Biomarkers of Exposure and Effect in Agriculture Study. Occup Environ Med. 2019 Jul;76(7):467-70.
46. Strelitz J, Engel LS, Keifer MC. Blood acetylcholinesterase and Butyrylcholinesterase as Biomarkers of Cholinesterase Depression Among Pesticide Handlers. Occup Environ Med. 2014;71(12):842-7.

47. Kaur K, Kaur R. Occupational Pesticide Exposure, Impaired DNA Repair, and Diseases. Indian J Occup Environ Med. 2018 MayAug;22(2):74-81.

48. Aroonvilairat S, Kespichayawattana W, Sornprachum T, Chaisuriya P, Siwadune T, Ratanabanangkoon K. Effect of Pesticide Exposure on Immunological, Hematological and Biochemical Parameters in Thai Orchid Farmers-A Cross-sectional Study. Int J Environ Res Public Health. 2015 May; 12(6):5846-61.

Have you read the current trends in Medical and Health Research in the Philippines?

\title{
Acta Medica Philippina The National Health Science Journal
}

\author{
Access Online: www.actamedicaphilippina.upm.edu.ph
}

